\title{
MicroRNA-214 suppresses growth, migration and invasion through a novel target, high mobility group AT-hook 1, in human cervical and colorectal cancer cells
}

\author{
Karthik Subramanian Chandrasekaran ${ }^{1}$, Anusha Sathyanarayanan ${ }^{1}$ and Devarajan Karunagaran ${ }^{*}, 1$ \\ ${ }^{1}$ Department of Biotechnology, Bhupat and Jyoti Mehta School of Biosciences, Indian Institute of Technology Madras, Chennai, \\ Tamil Nadu 600036, India
}

Background: MicroRNA-214 (miR-214) has been shown to act as a tumour suppressor in human cervical and colorectal cancer cells. The aim of this study was to experimentally validate high mobility group AT-hook 1 as a novel target for miR-214-mediated suppression of growth and motility.

Methods: HMGA1 and miR-214 expression levels were estimated in cervical and colorectal clinical specimens using qPCR. HMGA1 $3^{\prime}$ untranslated region luciferase assays were performed to validate HMGA1 as a target of miR-214. Effect of altering the expression of miR-214 or HMGA1 on proliferation, migration and invasion of human cervical and colorectal cancer cells was investigated.

Results: miR-214 expression was poor while that of HMGA1 was high in cervical and colorectal cancer tissues. miR-214-reexpression or HMGA1 downregulation inhibited proliferation, migration and invasion of cancer cells while miR-214 inhibition had opposite effects. miR-214 was demonstrated to bind to the wild-type $3^{\prime}$ untranslated region of HMGA1 but not with its mutant.

Conclusions: Low expression of miR-214 concurrent with elevated levels of HMGA1 may contribute to cervical and colorectal cancer progression. miR-214-mediated regulation of HMGA1 is a novel mechanism for its tumour-suppressive actions in human cervical and colorectal cancer cells and opens up avenues for novel therapeutic strategies for these two cancers.

Cervical cancer $(\mathrm{CaCx})$ is common among women predominantly in the developing countries (Hawes and Kiviat, 2002), and in India, it is the most common cancer affecting women (Sankaranarayanan et al, 1996). Human papilloma virus (HPV) is the major risk factor for cervical cancer (Bouallaga et al, 2000), but independently, alterations in tumour-suppressor genes and/or oncogenes may also be necessary for cervical cancer progression (Zur Hausen, 1996). Although colorectal cancer (CRC) earlier had the lowest rates of incidence in Asian countries (Haggar and Boushey, 2009), in the past few years, Asia has witnessed a rapid increase in CRC incidence particularly in the developing countries, including India (Mohandas, 2011; Moghimi-Dehkordi, 2012). MicroRNAs are $\sim 22$ nucleotide long, small RNA molecules that modulate gene expression transcriptionally or posttranscriptionally by mainly binding to the $3^{\prime}$ untranslated region (UTR) of their target genes (Calin et al, 2002). miRNAs constitute unique expression signatures and modulate cellular signalling pathways in many cancers, including $\mathrm{CaCx}$ (Hu et al, 2010; Pereira et al, 2010) and CRC (Chen et al, 2015; Hur et al, 2015). miR-214 functions as a tumour suppressor by downregulating oncogenes, such as GALNT7, Bcl2l2 and TFAM in CaCx (Yang et al, 2009; Peng et al, 2012; Wang et al, 2013; Wen et al, 2014) and FGF-1 and ARL2 in CRC (Chen et al, 2014; Long et al, 2015), but the actual underlying mechanisms are yet to be elucidated. The high mobility group AT-hook (HMGA) proteins are non-histone chromosomal proteins involved in DNA transcription, replication,

*Correspondence: Dr D Karunagaran; E-mail: karuna@iitm.ac.in

Received 25 March 2016; revised 9 June 2016; accepted 12 July 2016; published online 18 August 2016

(c) 2016 Cancer Research UK. All rights reserved 0007-0920/16 
recombination and repair (Cleynen and Van de Ven, 2008) and, as recently shown, in the regulation of metabolism (Qiu et al, 2014, 2015). HMGA proteins are easily detected in embryonic, neoplastic and proliferating undifferentiated cells but not so in non-neoplastic human adult tissues (Resar, 2010). They were first discovered in CaCx cells (Lund et al, 1983) and subsequently shown to have an oncogenic role during $\mathrm{CaCx}$ initiation, progression and metastasis by cooperating with HPV18 E6/E7 oncoproteins and inactivating p53 (Bandiera et al, 1998; Mellone et al, 2008). Its enhanced expression correlates with tumorigenesis and metastasis in human CRC (Fedele et al, 1996; Huang et al, 2009). Importantly, cisregulatory elements in the $3^{\prime} \mathrm{UTR}$ mediate posttranscriptional regulation of HMGA1 (Borrmann et al, 2001). Indeed, in leukaemia, bladder and prostate cancers, HMGA1 expression is modulated by different miRNAs targeting its $3^{\prime} \mathrm{UTR}$ (Kaddar et al, 2009; Wei et al, 2011; Lin et al, 2013). In the present study, $m i R-214$ is demonstrated to directly target wild-type $3^{\prime} \mathrm{UTR}$ of $H M G A 1$ and reduce its endogenous expression in $\mathrm{CaCx}$ and $\mathrm{CRC}$ cells. Downregulation of HMGA1 expression by $m i R-214$ or siRNA-HMGA1 significantly inhibits proliferation, migration and invasion of $\mathrm{CaCx}$ and $\mathrm{CRC}$ cells. Thus novel mechanistic basis for the tumour-suppressive actions of $m i R-214$ is revealed unraveling new therapeutic opportunities.

\section{MATERIALS AND METHODS}

Human $\mathrm{CaCx}$ and $\mathrm{CRC}$ tissue samples. Fresh $\mathrm{CaCx}$ tissue samples were collected from consenting patients undergoing treatment for $\mathrm{CaCx}$ at the Institute of Obstetrics and Gynaecology, Chennai, India. Normal fresh cervical tissues were obtained from patients undergoing hysterectomy for various non-malignant reasons. Fresh CRC tissue samples and adjacent normal tissues were collected from consenting patients undergoing treatment for CRC at the Apollo Hospitals, Chennai, India. The study was approved by the Institutional Ethics Committee of Indian Institute of Technology Madras.

Cell lines. Human cervical cancer cell lines, SiHa, CaSki and C33A, and colorectal cancer cell lines, SW480 and SW620, were maintained in Dulbecco's Modified Eagle's Medium (DMEM) (Life Technologies, Carlsbad, CA, USA) containing 10\% FBS (Life Technologies) and antibiotics (100 $\mathrm{U} \mathrm{ml}^{-1}$ penicillin and $100 \mu \mathrm{g} \mathrm{ml}^{-1}$ streptomycin) in a humidified atmosphere of $5 \% \mathrm{CO}_{2}$ at $37^{\circ} \mathrm{C}$.

RNA and plasmid transfection. miRNA-control (no. CN001000-01-20), miR-214 mimic (no. C-301153-01), siRNA-control (no. D-001220-01-20), siRNA-HMGA1 (no. M-004597-02), antimiR-control (no. IN-002005-01-20 or antimiR-214 (no. IH301153-02-0005) were obtained from GE Healthcare Dharmacon (Lafayette, CO, USA). Transient transfections of the above (with $5 \mathrm{~nm}$ of miRNA and antimiR mimics and $50 \mathrm{nM}$ of siRNA mimics) into $\mathrm{CaCx}$ and $\mathrm{CRC}$ cells were achieved using Lipofectamine RNAiMAX (no. 13778150, Life Technologies) while pcDNA 3.1, pcDNA 3.1-miR-214, pIRES (vector control), pIRES-HMGA1 (kind gift from Edward Whang, Addgene plasmid no. 13466, Addgene, Cambridge, MA, USA), 3'UTR reporter plasmid constructs were transfected using linear polyethyleneimine (no. 23966-2, MW 25000, procured from Polysciences, Warrington, PA, USA) at a ratio of $5: 1$ to DNA. Combinations of miRcontrol+pIRES, miR-214+pIRES, miR-control+pIRES-HMGA1, miR-214+pIRES-HMGA1 were transfected using DharmaFECT Duo (no. T-2010-01, GE Healthcare Dharmacon).

Western blotting. Total cell lysates were prepared by incubating cells in RIPA lysis buffer $(150 \mathrm{~mm} \mathrm{NaCl}, 1 \%$ NP-40, $0.5 \%$ deoxycholate and $1 \%$ SDS) on ice for $1 \mathrm{~h}$, and protein concentration was quantified by Bradford's method according to the manufacturer's protocol (Bio-Rad, Hercules, CA, USA). Samples
(50 $\mu \mathrm{g}$ protein) were resolved on $10 \%$ SDS-PAGE and transferred to a PVDF membrane (Immunoblot, Bio-Rad) using a Bio-Rad Mini PROTEAN III apparatus. Anti-HMGA1 (no. 7777S) and anti-ACTB (no. A5441) antibodies were purchased from Cell Signaling (Danvers, MA, USA) and Sigma-Aldrich (St Louis, MO, USA), USA, respectively, while anti-mouse IgG-peroxidase-conjugate (no. 115-035-003) and anti-mouse IgG-peroxidase-conjugate (no. 111-035-003) secondary antibodies were bought from Jackson Laboratories (West Grove, PA, USA). Bands detected using the Enhanced Chemiluminescence Kit (Bio-Rad) were visualised using ChemiDoc (Bio-Rad) and analysed by densitometry (Image Lab, Bio-Rad). ACTB was used as an internal control. Experiments were repeated at least once to confirm the results obtained earlier.

RNA isolation and real-time quantitative PCR. Tissue samples were ground and RNA was extracted using the manufacturer's protocol (TRIzol, Life Technologies) and RNA was also isolated from cells using TRIzol (Life Technologies). Mature miRNA levels were estimated by performing stem-loop reverse transcription followed by quantitative PCR; reverse transcription by MMLV reverse transcriptase (Life Technologies) was performed using miR-214-specific and RNU6-specific stem-loop primers. PCR amplification of $m i R-214$ or RNU6 was performed using a forward primer specific for $m i R-214$ or RNU6 (internal control) and a universal reverse primer. For estimating HMGA1 mRNA levels, reverse transcription was carried out by MMLV reverse transcriptase (Life Technologies) using oligo-dT and amplified using appropriate gene-specific PCR primers. Detection and quantitation of HMGA1 or ACTB (internal control) was carried out using the DyNAmo ColorFlash SYBR Green qPCR Kit reagent (no. F416L, Thermo Scientific, Waltham, MA, USA) on Eppendorf realplex4 Mastercycler epgradient S (Eppendorf, Hamburg, Germany). Relative expression levels of genes analysed were calculated using $2^{-\Delta \mathrm{CT}}$ (tissue samples) or $2^{-\Delta \Delta \mathrm{CT}}$ (cancer cells) method.

$3^{\prime}$ UTR luciferase assays. HMGA1 $3^{\prime}$ UTR that contains putative binding sites for the $m i R-214$ was amplified from human genomic DNA using Phusion high-fidelity DNA polymerase (New England Biolabs, Ipswich, MA, USA) and cloned into the $3^{\prime}$ UTR of Renilla luciferase gene in the psiCHECK-2 reporter vector (Promega, Madison, WI, USA). The miR-214-binding site was mutated by substituting five out of the six bases in the miRNA-binding sequence (seed sequence) in the $3^{\prime}$ UTR of HMGA1 using appropriate primers and the mutant construct thus synthesised was used as a negative control. $\mathrm{CaCx}$ or $\mathrm{CRC}$ cells were cotransfected with pcDNA3.1 or pcDNA3.1-miR-214 and the wildtype or mutant $3^{\prime} \mathrm{UTR}$ luciferase constructs in a 24 -well format, and $24 \mathrm{~h}$ posttransfection, cells were lysed using Passive Lysis Buffer, and Renilla luciferase activity was measured using the Dual Luciferase Assay Kit (no. A2492, Promega) and a luminescence plate reader (Molecular Devices Inc., Sunnyvale, CA, USA), wherein firefly luciferase acted as the internal control.

Migration and invasion assays. Migration assays were performed by transfecting $\mathrm{CaCx}$ or $\mathrm{CRC}$ cells with $m i R-214$ or siRNAHMGA1 or antimiR-214 or respective controls and then seeding $5 \times 10^{4}$ cells in DMEM onto the upper part of each Transwell chamber (BD Biosciences, Franklin Lakes, NJ, USA) and adding $10 \%$ FBS containing DMEM to the lower part of the chamber. Cells adhering to the bottom of the Transwell membrane were stained with $0.1 \%$ crystal violet $48 \mathrm{~h}$ later and images were obtained using an Olympus TL4 inverted light microscope (Shinjuku, Tokyo, Japan). In addition, stain was collected from stained cells by washing with $10 \%$ acetic acid and quantified by measuring absorbance at $595 \mathrm{~nm}$ (Saito et al, 1997) using a Bio-Rad Model 680 microplate reader (Bio-Rad, Shinagawa-ku, Tokyo, Japan). Invasion assays were performed in a similar manner but by 
allowing the cells to migrate through a GelTrex-coated (no. A15696-01, Life Technologies) layer in the upper part of a Transwell chamber.

BrdU incorporation assays. Proliferation assays were performed by transfecting $0.7 \times 10^{4}$ cells with $m i R-214$ or antimiR-214 or siRNAHMGA1 or respective controls and, $48 \mathrm{~h}$ posttransfection, were examined using the BrdU Cell Proliferation Assay Kit (no. 6813S, Cell Signaling) according to the manufacturer's protocol.

TCGA data analysis. TCGA open access data directory (http:// cancergenome.nih.gov/) was used to obtain miRNA and mRNA expression data sets for human $\mathrm{CaCx}$ and CRC tumours. Normalised TCGA level 3 miRNA-seq and RNA-seqV2 data were compiled using $\mathrm{R}$ studio and used for assessing the expression of miRNA and mRNA. These linear sequencing data expression values were then used to compute Pearson product-moment correlation coefficient.

Statistical analysis. qPCR was performed in duplicates for all the clinical tissue specimens and mean expression was calculated within normal or cancer tissue subsets. As paired normal specimens were available only in the case of colorectal tumour, miR-214 or HMGA1 expression in a tumour was normalised to its paired normal counterpart. One-way ANOVA test was performed to evaluate fold expression relative to mean. In the case of cervical clinical specimens, mean values for each data set (tumour or normal) were calculated. In the case of miR-control-, miR-214-, siR-control-, siHMGA1-, antimiR-control- or antimiR-214-transfected cells, three independent experiments were conducted for RNA quantitation (in vitro), BrdU incorporation, migration and invasion assays, and after appropriate normalisation, s.e.m. was plotted. After performing unpaired $t$-tests, $P$-values were calculated and represented as ${ }^{\star} P \leqslant 0.05,{ }^{* *} P \leqslant 0.01,{ }^{\star *} P \leqslant 0.001$ or ${ }^{\star * *} P \leqslant 0.0001$.

\section{RESULTS}

Expression of $m i R-214$ is lower while that of HMGA1 is higher in both human cervical and colorectal tumours than in their corresponding normal tissues. $m i R-214$ is a known tumoursuppressor miRNA in cervical $(\mathrm{CaCx})$ and colorectal (CRC) cancers and acts by downregulating a few oncogenes as is the case with many tumour-suppressor miRNAs. A putative, conserved, 6mer, miR-214-binding sequence located at 308-314 bases downstream in the HMGA1 $3^{\prime}$ UTR was identified using TargetScan. HMGA1 was of particular interest among the target genes identified because of its positive roles in cancer cell proliferation and invasion in $\mathrm{CaCx}$ and $\mathrm{CRC}$ cells. Prompted by the inverse correlation in the expression of this miRNA-target pair deduced from previous reports that studied miR-214 or HMGA1 expression separately (Fedele et al, 1996; Bandiera et al, 1998; Yang et al, 2009; Chen et al, 2014), these two were analysed together by TCGA data analysis or quantitative PCR in patient samples to strengthen the possibility of the existence of a regulatory mechanism. TCGA analysis showed a clear inverse correlation between $m i R-214$ and HMGA1 both in $\mathrm{CaCx}$ and CRC (Figures $1 \mathrm{~A}$ and $\mathrm{B}$ ). Pearson correlation coefficients of $-0.239(P=0.0019)$ and -0.274 $(P=0.0005)$ were obtained for $\mathrm{CaCx}$ and $\mathrm{CRC}$ tumour samples, respectively. When a few samples of $\mathrm{CaCx}$ and $\mathrm{CRC}$ were analysed to check if this correlation existed in a local population, the same trend was found. Expression levels of mature miR-214 analysed in various samples fell into a lower range in $\mathrm{CaCx}$ tissues compared with normal tissues (Figure 1C), with mean values of 20.26 and 66.13, respectively. HMGA1 mRNA levels were found in a relatively higher, narrow range (Figure $1 \mathrm{D}$ ) in $\mathrm{CaCx}$ relative to normal tissues with mean values of 22.6 and 8.2, respectively. Similarly, miR-214 was found to be poorly expressed (mean $0.68 \pm 0.3$ ), whereas HMGA1 expression was higher (mean
$11.52 \pm 5.4)$ in CRC tissues than in their paired normal tissues (Figures $1 \mathrm{E}$ and $\mathrm{F}$ ). Expression levels of $m i R-214$ were higher in 4 out of the 20 CRC samples, whereas HMGA1 expression was lower in 1 out of the 20 tumours when compared with their paired normal tissues. These results showing an inverse relationship between the expression levels of miR-214 and HMGA1 in human $\mathrm{CaCx}$ and $\mathrm{CRC}$ together with the identification of a $m i R-214$ binding site in the HMGA1 $3^{\prime} \mathrm{UTR}$ suggested that $m i R-214$ may directly target and regulate $H M G A 1$.

HMGA1 is directly targeted by $m i R-214$. As the physiological effects of endogenous $m i R-214$ are difficult to ascertain owing to their low levels in $\mathrm{CaCx}$ and $\mathrm{CRC}$ cells, the miRNA was first re-expressed ectopically. $\mathrm{CaCx}$ and $\mathrm{CRC}$ cells transfected with $m i R$ 214 mimic showed 3-6 and 2-5 fold more expression, respectively, than their corresponding miR-control-transfected cells (Figure 2A). Maintaining this range of expression, the effect of reintroducing $m i R$ 214 on endogenous HMGA1 mRNA and protein levels was determined, and the results show that miR-214 decreased HMGA1 both at mRNA (Figure 2B) and protein (Figure 2D) levels in human $\mathrm{CaCx}$ and CRC cells. To confirm whether HMGA1 is targeted by miR-214 by binding to its $3^{\prime} \mathrm{UTR}$ (Figure 2C), HMGA1 3'UTR luciferase assays were performed and it was observed that reexpression of miR-214 decreased wild-type HMGA1 3'UTR-regulated luciferase activity by $\sim 30 \%$ in $\mathrm{C} 33 \mathrm{~A}, \sim 46 \%$ in CaSki, $\sim 30 \%$ in $\mathrm{SiHa}, \sim 25 \%$ in SW480 and $\sim 33 \%$ in SW620 cells but not in cells transfected with HMGA1 3'UTR-containing mutant miR-214-binding sites (Figure 2E), confirming that $m i R-214$ binds specifically to the $3^{\prime}$ UTR of HMGA1 to repress gene expression. Together, these results suggest that $m i R-214$ negatively regulates endogenous $H M G A 1$ expression by binding to its $3^{\prime} \mathrm{UTR}$ in $\mathrm{CaCx}$ and CRC cells.

Re-expression of $m i R-214$ inhibits proliferation, migration and invasion in $\mathrm{CaCx}$ and CRC cells. To evaluate whether $m i R-214$ mediated targeting and the consequent downregulation/repression of HMGA1 has a role in tumorigenesis, first the effect of ectopic expression of miR-214 on cell proliferation was studied using BrdU incorporation assay in $\mathrm{CaCx}(\mathrm{C} 33 \mathrm{~A}$ and $\mathrm{SiHa}$ ) and CRC (SW480 and SW620) cells. Re-expression of $m i R-214$ inhibited cell proliferation significantly in C33A by $\sim 28 \%$, SiHa by $\sim 13 \%$, SW 480 by $\sim 23 \%$ and SW620 by $\sim 18 \%$ (Figure $3 \mathrm{~A}$ ). As the $\mathrm{CaCx}$ and CRC cells used in the current study are known to exhibit migratory and invasive properties, these cells were next tested by re-expressing $m i R-214$ and it inhibited migration in C33A by $\sim 31 \%$, SiHa by $\sim 23 \%$ and SW 480 by $\sim 25 \%$ (Figure 3B) as well as invasion in $\mathrm{C} 33 \mathrm{~A}$ by $\sim 25 \%$, SiHa by $\sim 25 \%$ and SW 480 by $\sim 33 \%$ (Figure $3 \mathrm{C}$ ). These results confirm that reintroduction of $m i R-214$ suppresses the aggressive behaviour of $\mathrm{CaCx}$ and $\mathrm{CRC}$ cells by inhibiting their proliferation, migration and invasion.

HMGA1 knockdown inhibits proliferation, migration and invasion in $\mathrm{CaCx}$ and $\mathrm{CRC}$ cells. Given that $m i R-214$ may have many potential targets in $\mathrm{CaCx}$ and $\mathrm{CRC}$ cells, the antiproliferative effect of miR-214 may not be limited to repression of HMGA1. To check whether suppression of HMGA1 would simulate miR-214mediated effects, siRNA-mediated knockdown of HMGA1 was performed in $\mathrm{CaCx}$ and CRC cells (Figure 4A). Under these conditions, cell proliferation was inhibited by $10-40 \%$ (Figure $4 \mathrm{~B}$ ). Similarly, diminished levels of HMGA1 reduced migration (Figure 4C) by $30 \%$ as well as invasion (Figure $4 \mathrm{D}$ ) by $20-50 \%$. From these data, it is inferred that merely downregulating HMGA1 expression can inhibit proliferation, migration and invasion in $\mathrm{CaCx}$ and $\mathrm{CRC}$ cells, producing phenotypes comparable to miR-214 reintroduction.

Inhibition of $m i R-214$ enhances proliferation, migration and invasion in $\mathrm{CaCx}$ and $\mathrm{CRC}$ cells. Although the ectopic expression of $m i R-214$ effectively inhibited proliferation, migration and invasion in 
$\mathrm{CaCx}$ and $\mathrm{CRC}$ cells, whether the endogenous $m i R-214$ contributes to these phenomena remained to be elucidated. When the endogenous $m i R-214$ was inhibited using an antimiR, there was an increase in HMGA1 levels (Figure 5A) and cell proliferation (Figure 5B), migration
(Figure 5C) and invasion (Figure 5D) were also enhanced by $40-60 \%$, $30-45 \%$ and $20-60 \%$, respectively. From these data, it is ascertained that downregulating miR-214 enhances endogenous HMGA1 levels concurrently stimulating proliferation, migration and invasion of $\mathrm{CaCx}$
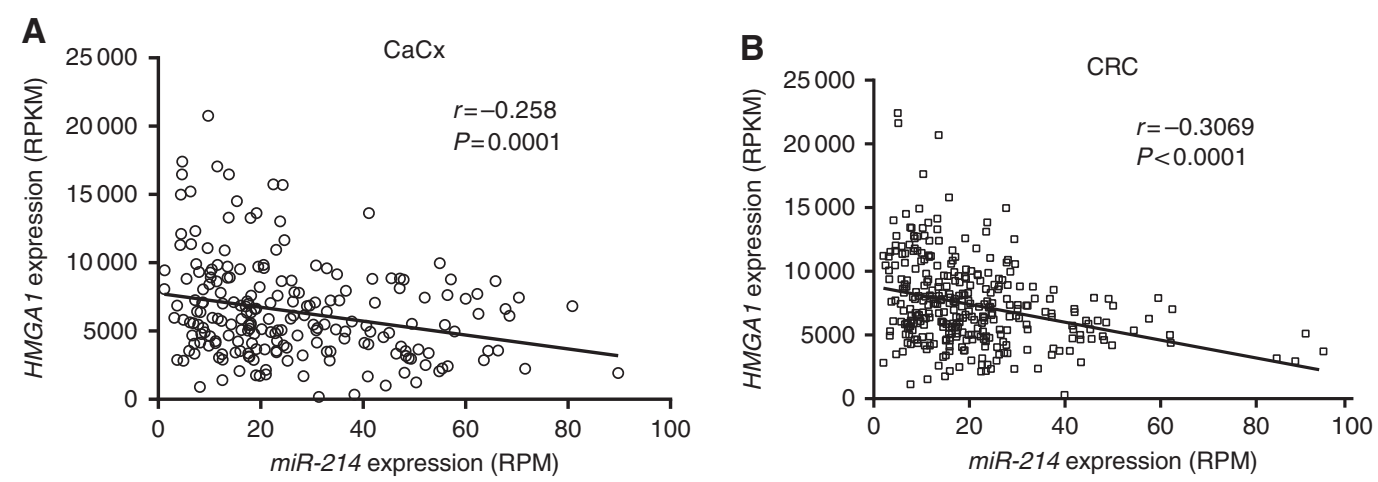

C
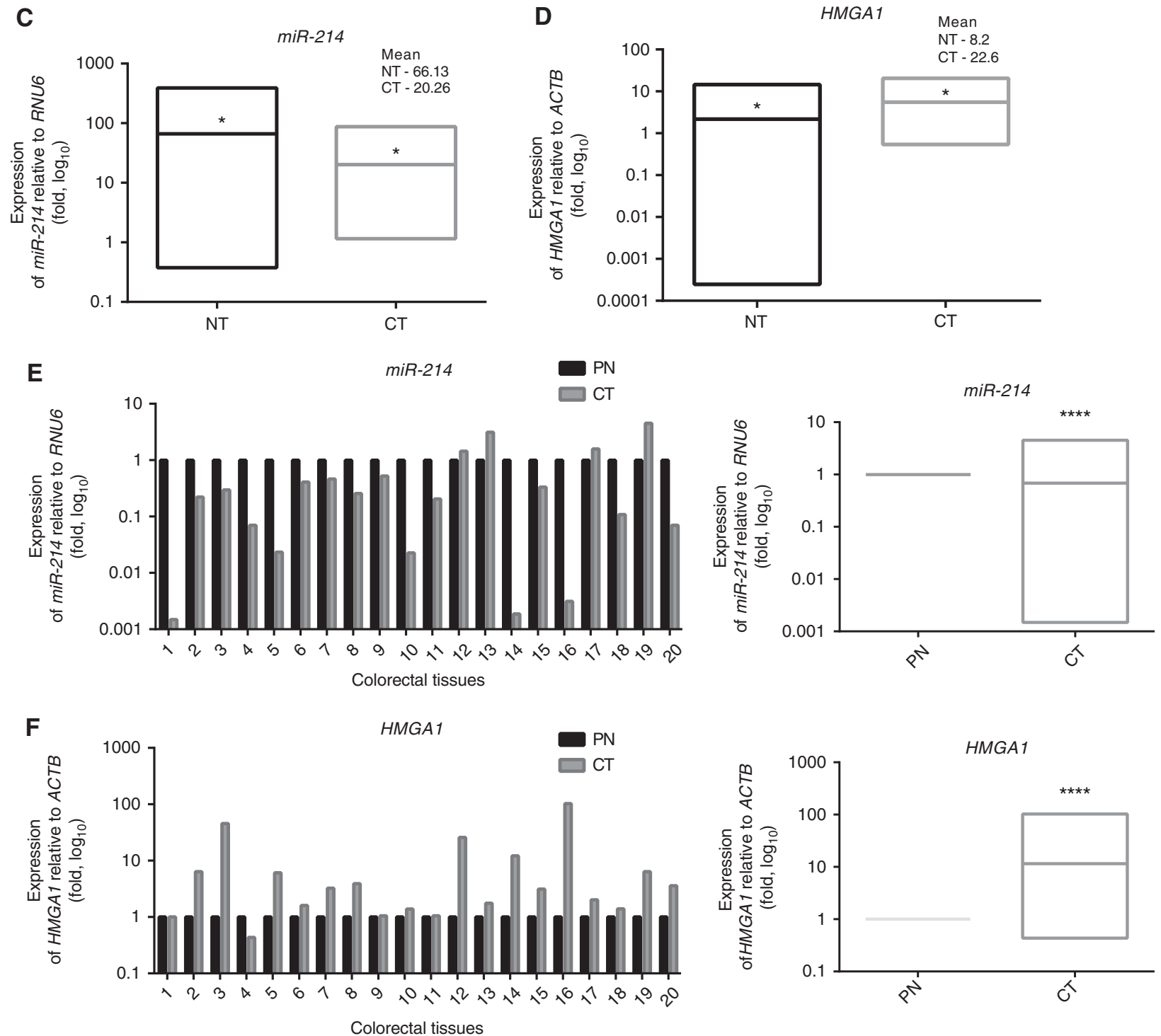

Figure 1. Relative expression levels of miR-214 and HMGA1 in normal and tumour cervical and colorectal tissues. TCGA database was used to plot Pearson product-moment correlation utilising normalised expression data for miR-214 (reads per million (RPM)) and HMGA1 (reads per kilobase per million mapped reads (RPKM)) from (A) 215 cervical and (B) t 322 colorectal umour samples. Quantitative PCR was performed to estimate the expression levels of (C) miR-214 from 20 normal cervical tissue specimens (NT) and 20 cervical tumour tissue specimens (CT) or (D) HMGA1 from 15 normal (NT) and tumour (CT) cervical tissue specimens. Expression levels of miR-214 and HMGA1, respectively, were normalised to that of RNU6 and ACTB. Similarly, 20 tumour (CT) and their paired normal (PN) colorectal tissue specimens were analysed for the expression levels of (E) miR-214 and (F) HMGA1. Solid lines in box plots represent mean values. $P$-values are represented as ${ }^{*} P \leqslant 0.05,{ }^{*} * \star * P 0.0001$. 
A

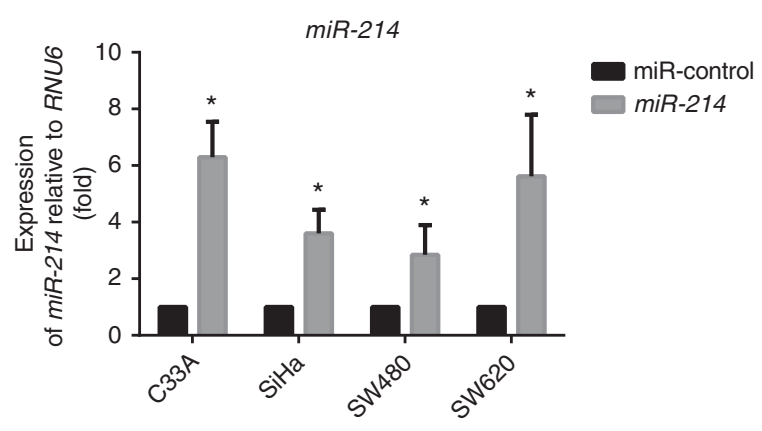

C

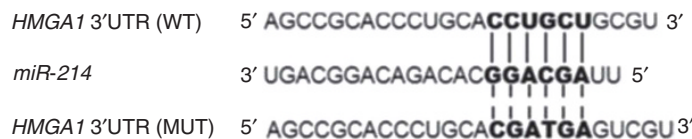

B

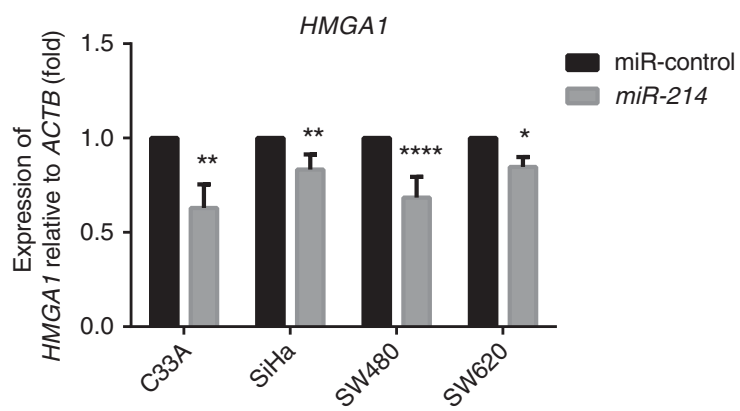

D
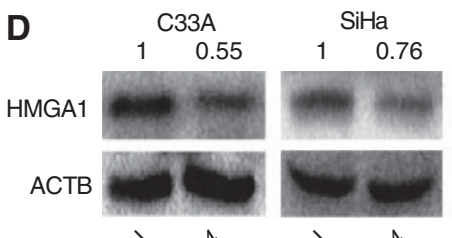

SW480
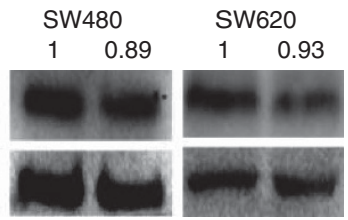

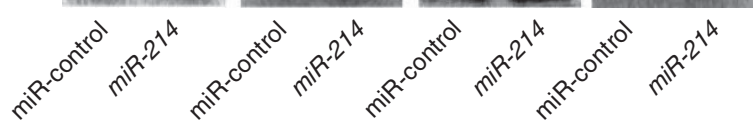

pcDNA-3.1 +WT

$\operatorname{miR}-214+\mathrm{WT}$

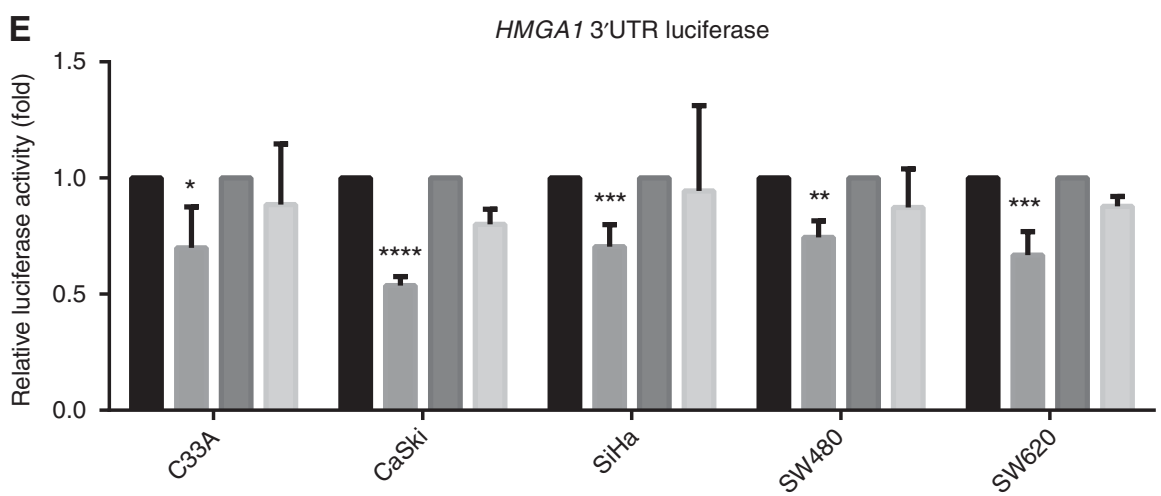

Figure 2. Changes in HMGA1 expression upon ectopic expression of miR-214 in CaCx and CRC cells. C33A, SiHa, SW480 or SW620 cells were transfected with control mimic (miR-control) or miR-214 mimic and the expression levels of (A) miR-214 or (B) HMGA1 were estimated by qPCR using RNU6 or ACTB, respectively, for normalisation, and (D) HMGA1 protein levels were estimated by western blotting and ACTB was used as a loading control. (E) psiCHECK-2 vector containing HMGA1 3'UTR either with wild-type miR-214-binding site (WT) or mutated site (MUT) was co-transfected with pcDNA 3.1 or pcDNA 3.1-miR-214 (miR-214) in CaCx and CRC cells and luciferase assays were performed. Renilla luciferase activity in miR-214transfected cells was normalised to that of vector-transfected cells and Firefly luciferase served as internal control. (C) Wild-type (WT) and mutant (MUT) miR-214-binding sites in HMGA1 $3^{\prime} U T R$ and miR-214 binding sequence (miR-214) are shown where solid lines and broken lines connect paired and unpaired bases from WT and MUT with those of miR-214, respectively. $P$-values are represented as ${ }^{\star} P \leqslant 0.05,{ }^{\star \star} P \leqslant 0.01,{ }^{\star \star \star} P \leqslant 0.001$ or ${ }^{\star \star \star \star} P \leqslant 0.0001$.

and CRC cells, producing cellular phenotypes that are considerably opposite to the ones produced by reintroduction of $m i R-214$ or independent downregulation of HMGA1.

miR-214 counters the effects of ectopically expressed HMGA1 on proliferation, migration and invasion in $\mathrm{CaCx}$ and $\mathrm{CRC}$ cells. As miR-214 effectively inhibited proliferation, migration and invasion in $\mathrm{CaCx}$ and $\mathrm{CRC}$ cells, it was pertinent to test the effects of expressing its target HMGA1 on these processes in the presence of $m i R-214$. Hence, $m i R-214$ and a $3^{\prime}$ UTR-less HMGA1 (unresponsive to miRNAs) were transfected individually or in combination in $\mathrm{CaCx}$ and CRC cells. As expected, miR-214 decreased HMGA1 expression and ectopic expression of HMGA1 increased it over endogenous levels, and notably, their combined ectopic expression still led to a decrease in HMGA1 in SiHa and SW480 cells (Figure 6A). Similar effects on proliferation (Figure 6B), migration (Figure 6C) and invasion (Figure 6D) were observed when this combination was used. Although miR-214 expression alone reduced proliferation by $14-29 \%$, migration by $22-30 \%$ and invasion by $15-27 \%$, ectopic expression of HMGA1 enhanced these. Combined expression of HMGA1 and miR-214 reduced cell proliferation, migration and invasion by $11-29 \%$, $15-37 \%$ and $20-25 \%$, respectively, compared with cells transfected with miR-control and vector-control. Taken together, these results ascertain that the tumour-suppressive action of $m i R-214$ prevails over the protumorigenic effects of HMGA1 even if it is ectopically expressed over and above the already abundant endogenous levels in $\mathrm{CaCx}$ and $\mathrm{CRC}$ cells.

\section{DISCUSSION}

In recent years, miRNAs have been increasingly demonstrated to have crucial roles in gene regulation, cellular signalling, carcinogenesis and in related processes, including metastasis and epithelial-to-mesenchymal transition (Suzuki et al, 2014; Kuninty 

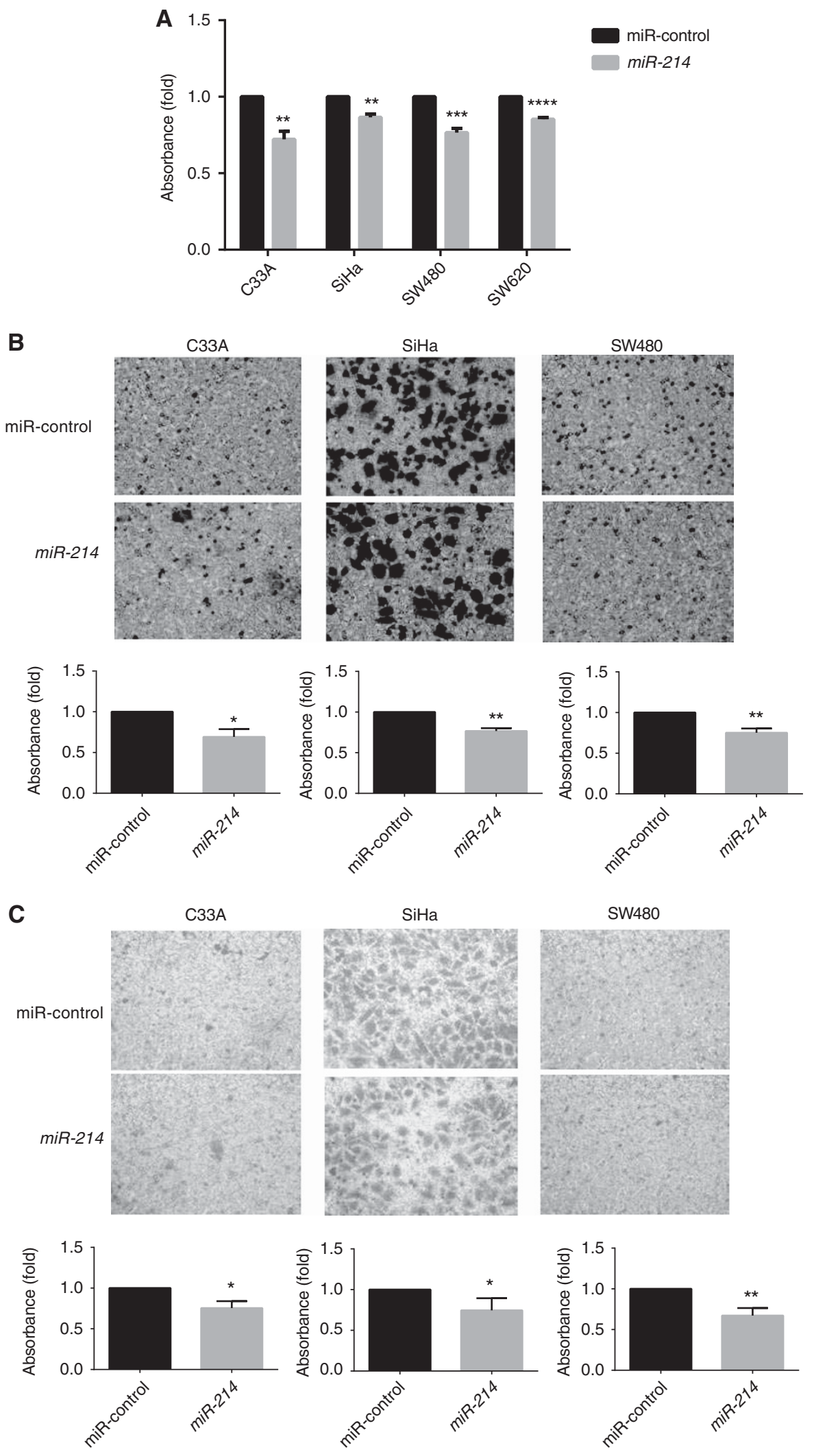

Figure 3. Effect of ectopic expression of miR-214 on proliferation, migration and invasion. C33A, SiHa, SW480 or SW620 cells were transfected with control mimic (miR-control) or miR-214 mimic and subsequently, (A) BrdU incorporation, (B) migration and (C) invasion were quantified by measuring absorbance. Absorbance values obtained with BrdU or $0.1 \%$ crystal violet for miR-214-transfected cells were normalised with those obtained for miR-control-transfected cells. Representative images for migration and invasion are displayed above quantitation. $P$-values are represented as ${ }^{*} P \leqslant 0.05,{ }^{\star \star} P \leqslant 0.01,{ }^{\star \star \star} P \leqslant 0.001$ or ${ }^{\star \star \star \star} P \leqslant 0.0001$. A full colour version of this figure is available at the British Journal of Cancer journal online. 
A

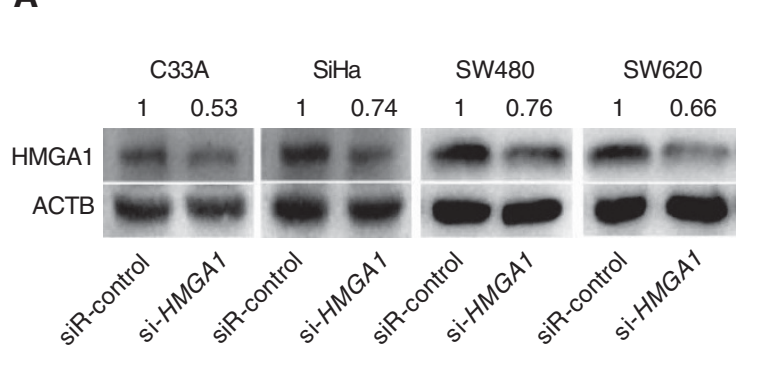

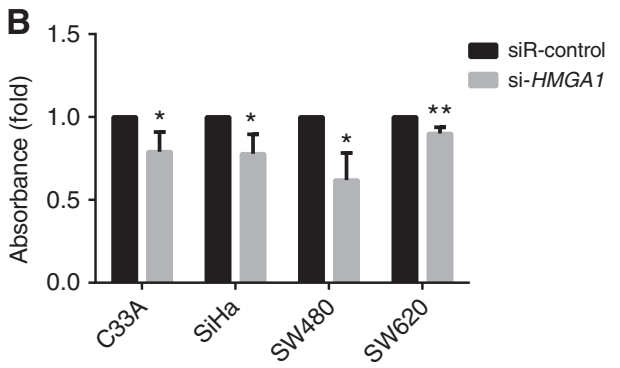
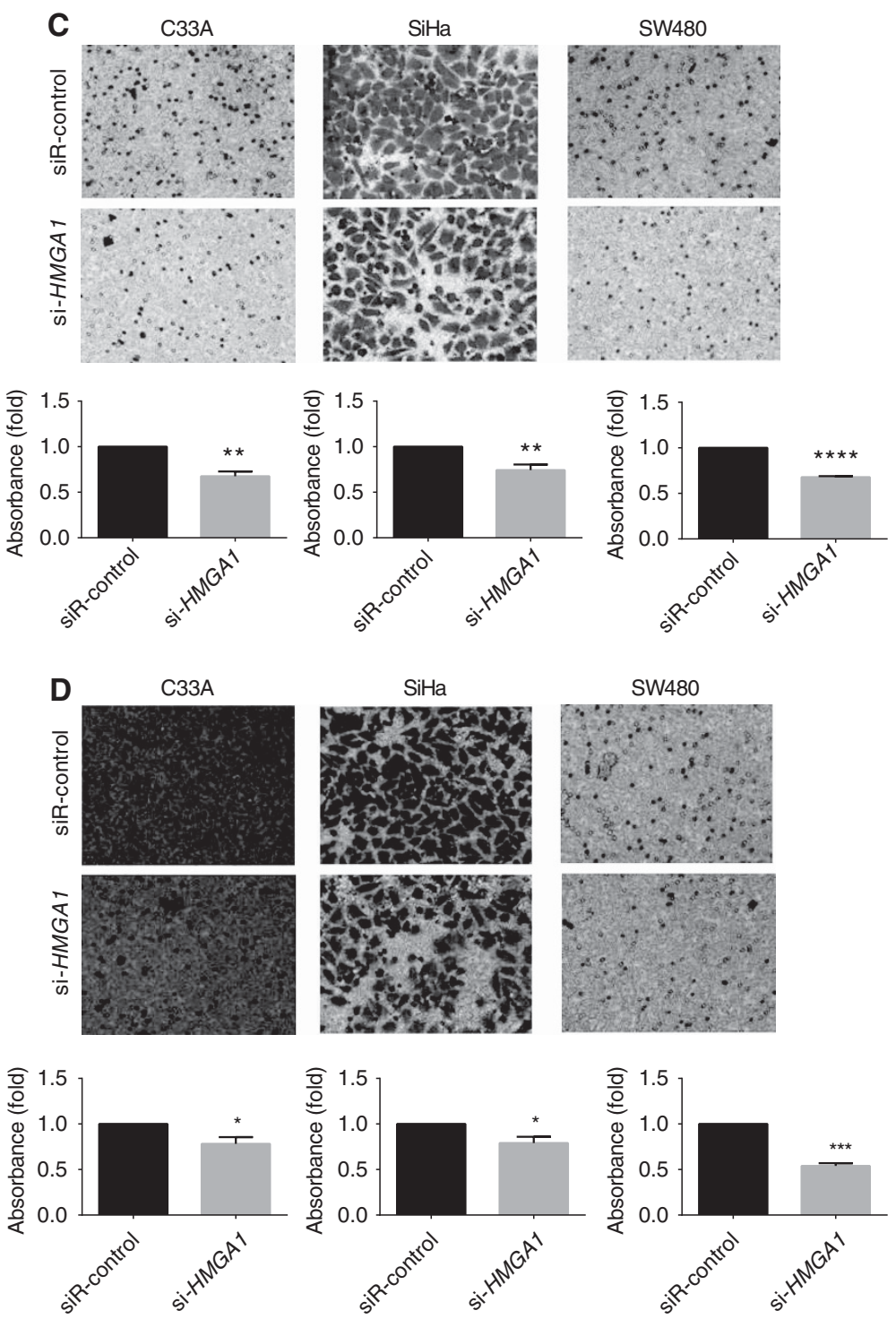

Figure 4. Changes in proliferation, migration and invasion assays upon knockdown of HMGA1. (A) CaCx or CRC cells were transfected with control siRNA (siR-control) or siRNA-HMGA1 (si-HMGA1) and the expression of HMGA1 was checked by western blotting. (B) BrdU incorporation, (C) migration and (D) invasion assays were quantified by measuring absorbance. Absorbance values obtained for si-HMGA1-transfected cells were normalised with those obtained for siR-control-transfected cells. Representative images for migration and invasion are displayed above quantitation. $P$-values are represented as ${ }^{\star} P \leqslant 0.05,{ }^{\star \star} P \leqslant 0.01,{ }^{\star \star \star} P \leqslant 0.001$ or ${ }^{\star \star \star \star} P \leqslant 0.0001$.

et al, 2016). miRNAs function by modulating the expression of several target genes simultaneously and can act as oncomirs by silencing the expression of tumour-suppressor targets and conversely can target oncogenes and behave as tumour-suppressor miRNAs (Esquela-Kerscher and Slack, 2006). Previously, it has been demonstrated that miR-29b downregulates canonical Wnt signalling and consequently inhibits colorectal cancer cell proliferation and anchorage-independent growth (Subramanian et al,
2014), whereas miR-106b enhances migration and invasion in nonsmall cell lung carcinoma cells by suppressing $\beta$-TRCP2 (Savita and Karunagaran, 2013). Present data obtained from human cervical and colorectal clinical specimens and those extracted from TCGA suggest poor expression of $m i R-214$ in these tumours, confirming earlier reports in these cancers. Inhibition of growth, migration and invasion in $\mathrm{CaCx}$ and $\mathrm{CRC}$ upon miR-214 reexpression are consistent with earlier data (Peng et al, 2012; Chen 
A

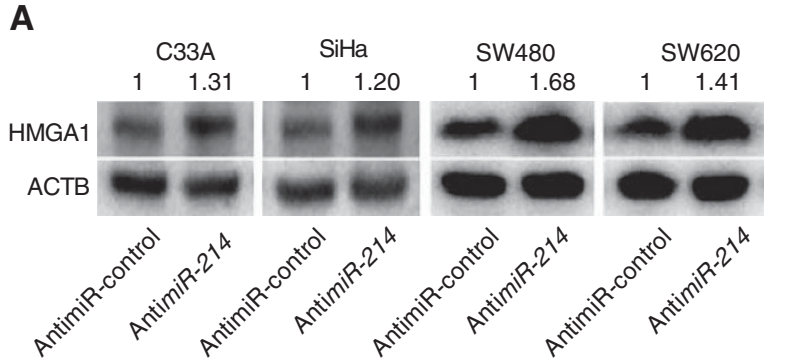

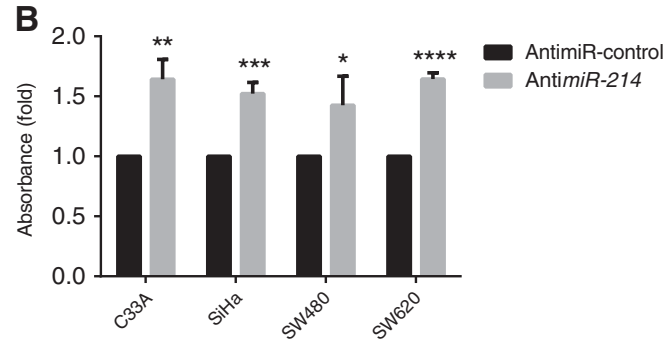

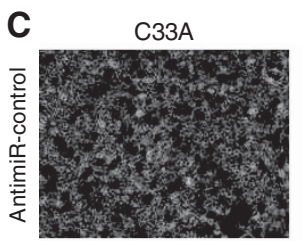

$\mathrm{SiHa}$
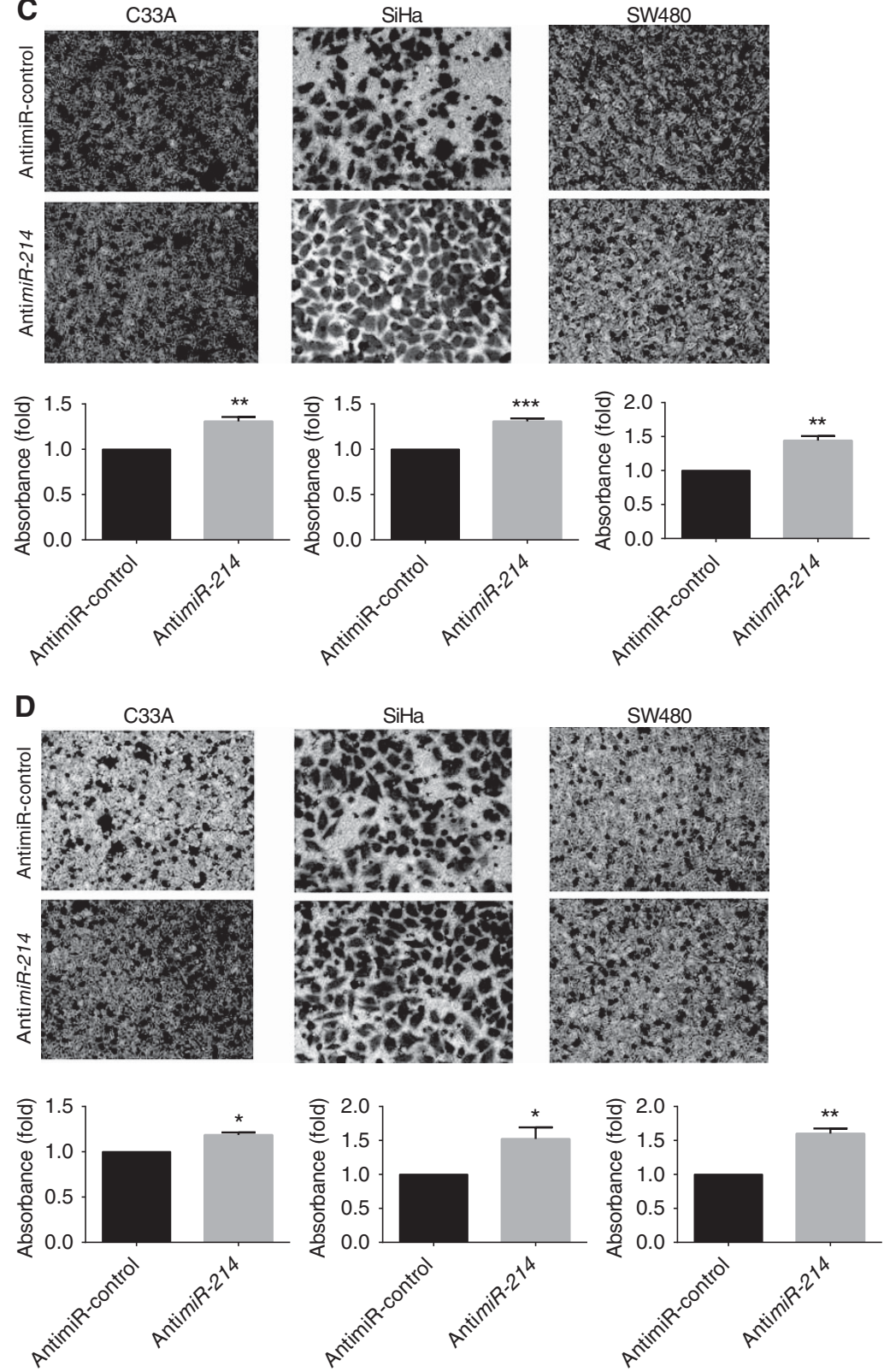

Figure 5. Effect of antimiR-214 on proliferation, migration and invasion. (A) CaCx or CRC cells were transfected with control antimiR (antimiRcontrol) or antimiR-214 and the expression of HMGA1 was checked by western blotting. (B) BrdU incorporation, (C) migration and (D) invasion assays were quantified by measuring absorbance. Absorbance values obtained for antimiR-214-transfected cells were normalised with those obtained for antimiR-control-transfected cells. Representative images for migration and invasion are shown above quantitation. $P$-values are represented as ${ }^{\star} P \leqslant 0.05,{ }^{\star \star} P \leqslant 0.01,{ }^{\star \star \star} P \leqslant 0.001$ or ${ }^{\star \star * \star *} P \leqslant 0.0001$.

et al, 2014). However, $m i R-214$ is highly expressed in melanoma (Penna et al, 2013), and gastric (Yang et al, 2013) cancers, and in ovarian cancer, it favours cell survival and cisplatin resistance by targeting the phosphate and tensin homolog (Yang et al, 2008), suggesting that it may function as an oncogene as well. These contradictory results are, however, not uncommon with miRNAs as the same miRNA may act as an oncomir in one cancer type and as a tumour suppressor in another cancer. For instance, miR-155 significantly contributes to growth in B-cell lymphoma (Pedersen et al, 2009) but sensitises triple-negative human breast cancer cells 
A

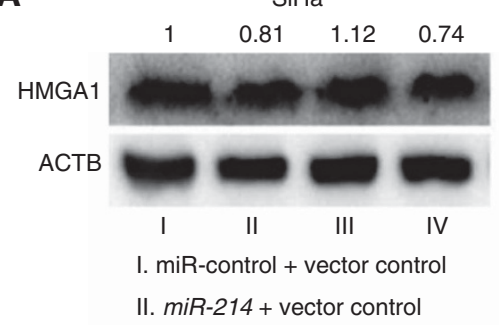

SW480

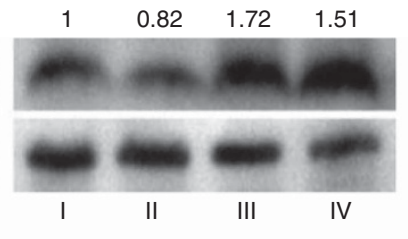

III. miR-control + HMGA1

IV. $m i R-214+$ HMGA1
B

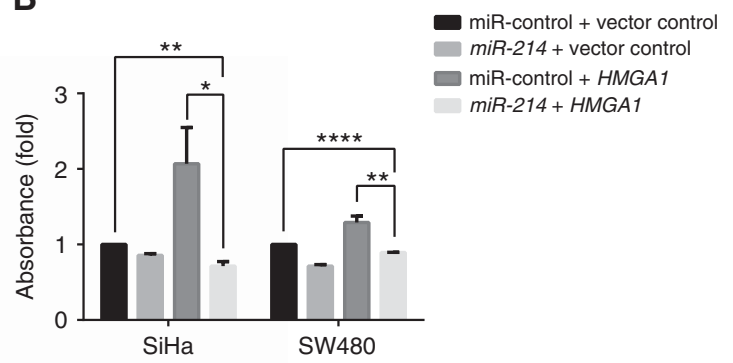

C
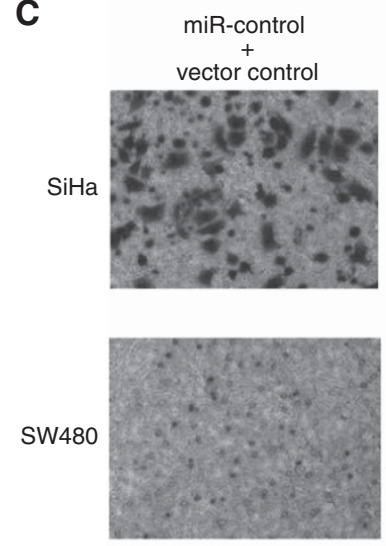

D
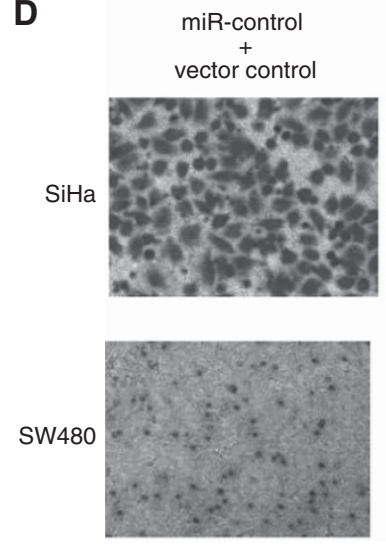
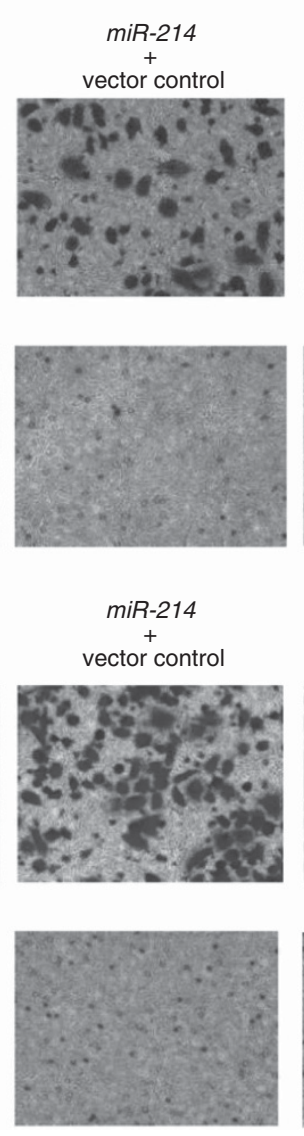

miR-control $\stackrel{+}{M}^{+} A 1$
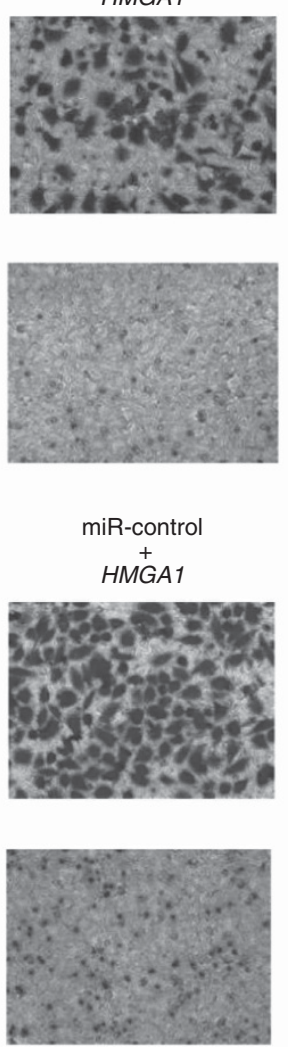
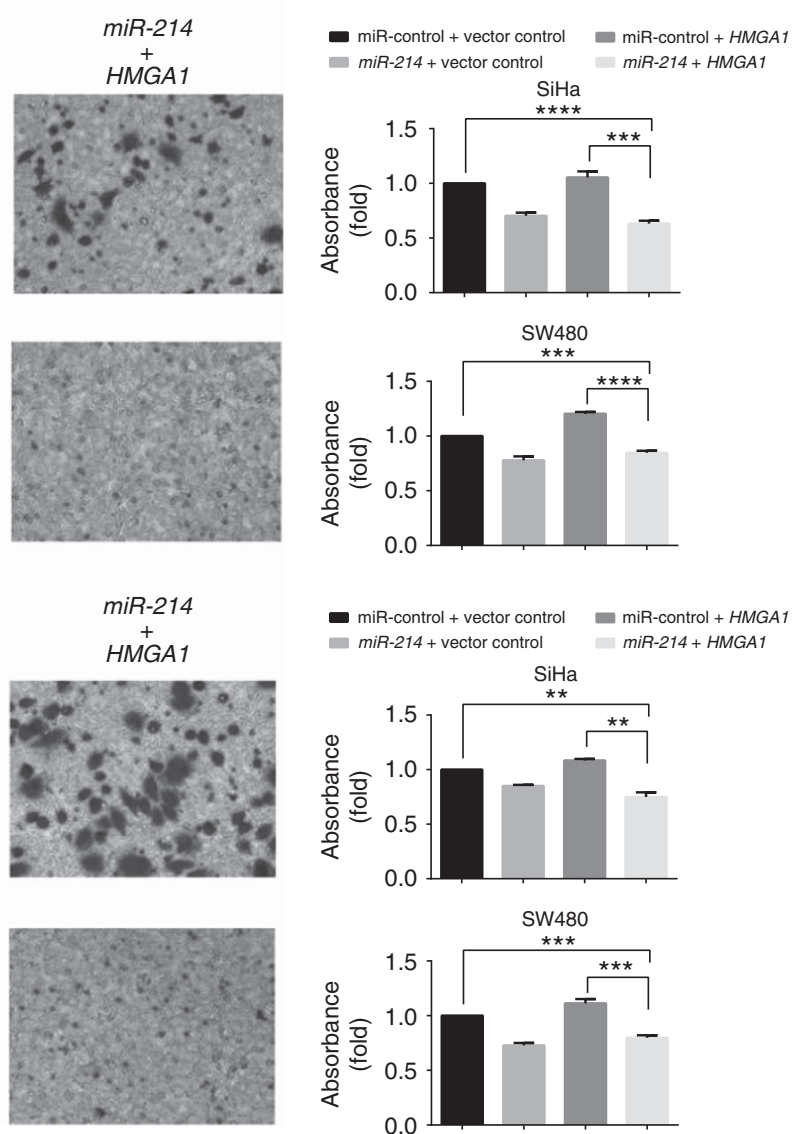

$\begin{array}{ll}\text { miR-control + vector control } & \text { miR-control + HMGA1 } \\ \text { miR-214 + vector control } & \text { miR-214 + HMGA1 }\end{array}$
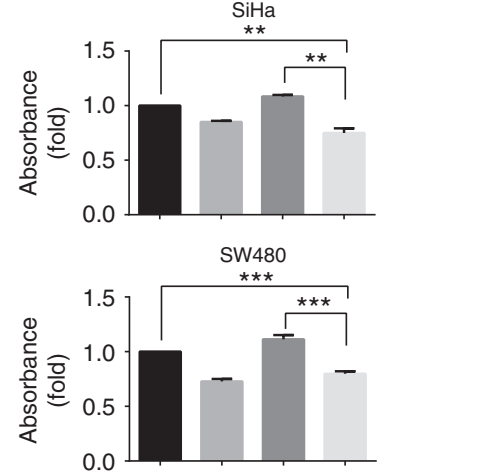

Figure 6. Changes in HMGA1-induced proliferation, migration and invasion upon reintroduction of miR-214. (A) CaCx or CRC cells were cotransfected with control miR (miR-control) or miR-214 either with vector control or HMGA1 and the expression of HMGA1 was checked by western blotting. (B) BrdU incorporation, (C) migration and (D) invasion were quantified by measuring absorbance. Absorbance values obtained for miR214 + HMGA1-transfected or miR-214-transfected or HMGA1-transfected cells were normalised with those obtained for miR-control + vector control-transfected cells. miR-214 + HMGA1-transfected or HMGA1-transfected cells were compared with miR-control + vector control-transfected cells to calculate statistical significance. Representative images for migration and invasion are shown alongside quantitation. $P$-values are represented as ${ }^{\star} P \leqslant 0.05,{ }^{\star \star} P \leqslant 0.01,{ }^{\star \star \star} P \leqslant 0.001$ or ${ }^{\star \star \star \star *} P \leqslant 0.0001$.

to infrared by targeting RAD51 (Gasparini et al, 2014). Ectopic expression of $m i R-214$ inhibited cell proliferation more effectively in C33A and SW480 than in SiHa and SW620 cells, and these differential and paradoxical effects are presumably due to differences in genetic background, microenvironment and the pattern of target gene expression in each cell type. Furthermore, multiple miRNAs may exhibit cooperative binding to binding sites on a single target gene (Lewis et al, 2003; Krek et al, 2005), facilitating the formation of complex regulatory networks.

Antithetical to the impairing effect of miR-214 re-introduction on the growth, migration and invasion of $\mathrm{CaCx}$ and $\mathrm{CRC}$ cells, the presence of HMGA1 is documented to aid tumorigenesis and its maintenance, crucial to metastasis (Reeves et al, 2001; Mellone et al, 2008; Belton et al, 2012; Xing et al, 2014). Downregulating
HMGA1 using siRNA suppressed cell proliferation, invasion and migration in this study in a manner comparable to re-expression of miR-214, suggesting that miR-214 mainly acts through HMGA1 or alternatively it emphasises a major role for HMGA1 on the regulation of tumour progression. Further, the finding in the current study that miR-214 could target HMGA1 $3^{\prime}$ UTR and inhibit its expression lends credence to its tumour-suppressive role. Although downregulation of HMGA1 by miR-16 in leukaemia (Kaddar et al, 2009), miR-142-3p in osteosarcoma (Xu et al, 2014), miR-26a in bladder cancer (Lin et al, 2013) and miR-296 in prostate cancer (Wei et al, 2011) led to inhibition of cancer cell growth and motility, present findings are the first to relate similar phenomena in $\mathrm{CaCx}$ and CRC cells. HMGA1 upregulates STAT3 expression in leukaemia (Hillion et al, 2008), is induced by TGF- $\beta$ 
signalling in breast carcinoma (Zu et al, 2015), cooperates with NF$\kappa \mathrm{B}$ (p65 Rel-A) and bolsters HPV E6/E7 expression via a positive autoregulatory loop in $\mathrm{CaCx}$ (Mellone et al, 2008) and sustains $\mathrm{Wnt} / \beta$-catenin pathway in CRC (Xing et al, 2014). Although a hitherto unknown mechanism by which HMGA1 may be regulated in $\mathrm{CaCx}$ and CRC is shown, it remains to be studied whether other miRNAs predicted to target HMGA1 may be able to regulate it simultaneously with $m i R-214$ or independent of it. That a potent oncogene such as HMGA1 is most effectively regulated by $m i R-214$ is demonstrated by the finding that the ectopic expression of a $3^{\prime}$ UTR-less HMGA1 did not act as a deterrant to $m i R-214$ in its inhibitory effects on proliferation, migration and invasion in $\mathrm{CaCx}$ and CRC cells and conclusively delineates the functional relevance of the antitumorigenic role of $m i R-214$ in these cancers, through regulation of HMGA1.

Current data indicate that poor expression of $m i R-214$ concomitant with elevated levels of HMGA1 may contribute to malignant phenotype in $\mathrm{CaCx}$ and $\mathrm{CRC}$. Thus the identification of HMGA1 as a major target gene for miR-214 in $\mathrm{CaCx}$ and CRC unleashes potential molecular mechanisms of tumorigenesis.

Novel and salient findings from this study in cervical and colorectal cancers are listed below.

(1) a hitherto unknown mechanism for the tumour-suppressive actions of $m i R-214$.

(2) miRNA-mediated regulation of $H M G A 1$, and

(3) siRNA-mediated downregulation of $H M G A 1$ and its effect on proliferation, migration and invasion.

\section{CONCLUSIONS}

This is the first report elaborating that $m i R-214$, whose attenuated expression in $\mathrm{CaCx}$ and $\mathrm{CRC}$ has been associated with poor prognosis in previous studies, functions as a tumour suppressor by negatively regulating expression of oncogene HMGA1. Downregulation of cellular HMGA1 alone affected cancer cells in a manner comparable to that of restoration of $m i R-214$ while inhibition of endogenous miR-214 resulted in elevated HMGA1 levels and a consequent amelioration of growth, migration and invasion. Further, ectopic expression of $m i R-214$ was able to thwart the protumorigenic effect of ectopically expressed HMGA1 and suppress cancer cell's growth and motility.

\section{ACKNOWLEDGEMENTS}

This work was supported by an exploratory research grant from the Centre for Industrial Consultancy and Sponsored Research, Indian Institute of Technology Madras (to DK and KSC) and by senior research fellowship (to AS) from the Council of Scientific and Industrial Research, Government of India. We thank Dr Prabhavathy Devan, Indian Institute of Technology Madras, Dr Radha Bai Prabhu, Institute of Obstetrics and Gynaecology and Government Hospital for Women and Children, Government of India and Dr Shankar Srinivasan, Consultant Medical Oncologist, Apollo Speciality Hospitals, Chennai, India for their help in procurement of clinical specimens and Dr Rao Srinivasa Rao, Nuffield Department of Surgical Sciences, University of Oxford, Oxford for his help in analysing data from TCGA. TCGA Research Network (http://cancergenome.nih.gov/) is acknowledged for providing access to their data. The pcDNAmiR-214 construct was a kind gift from Dr Cheng, Moffitt Cancer Center and Research Institute, Tampa, USA. The following were kind gifts:
C33A, SiHa, SW480 and SW620 cells from Dr Ygal Haupt, Peter MacCallum Cancer Centre, Victoria, Australia and CaSki cells from Dr Sudhir Krishna, National Centre for Biological Sciences, Bangalore, India.

CONFLICT OF INTEREST

The authors declare no conflict of interest.

\section{REFERENCES}

Bandiera A, Bonifacio D, Manfioletti G, Mantovani F, Rustighi A, Zanconati F, Fusco A, Di Bonito L, Giancotti V (1998) Expression of HMGI(Y) proteins in squamous intraepithelial and invasive lesions of the uterine cervix. Cancer Res 58: $426-431$.

Belton A, Gabrovsky A, Bae YK, Reeves R, Iacobuzio-Donahue C, Huso DL, Resar LMS (2012) HMGA1 induces intestinal polyposis in transgenic mice and drives tumor progression and stem cell properties in colon cancer cells. PLoS One 7: e30034.

Borrmann L, Wilkening S, Bullerdiek J (2001) The expression of HMGA genes is regulated by their $3^{\prime} \mathrm{UTR}$. Oncogene 20: 4537-4541.

Bouallaga I, Massicard S, Yaniv M, Thierry F (2000) An enhanceosome containing the Jun B/Fra-2 heterodimer and the HMG-I(Y) architectural protein controls HPV 18 transcription. EMBO Rep 1: 422-427.

Calin GA, Dumitru CD, Shimizu M, Bichi R, Zupo S, Noch E, Aldler H, Rattan S, Keating M, Rai K, Rassenti L, Kipps T, Negrini M, Bullrich F, Croce CM (2002) Frequent deletions and down-regulation of micro- RNA genes miR15 and miR16 at 13q14 in chronic lymphocytic leukemia. Proc Natl Acad Sci USA 99: 15524-15529.

Chen D-L, Wang Z-Q, Zeng Z-L, Wu W-J, Zhang D-S, Luo H-Y, Wang F, Qiu M-Z, Wang D-S, Ren C, Wang F-H, Chiao LJ, Pelicano H, Huang P, Li Y-H, Xu R-H (2014) Identification of microRNA-214 as a negative regulator of colorectal cancer liver metastasis by way of regulation of fibroblast growth factor receptor 1 expression. Hepatology 60: 598-609.

Chen XJ, Shi KQ, Wang YQ, Song M, Zhou W, Tu HX, Lin Z (2015) Clinical value of integrated-signature miRNAs in colorectal cancer: miRNA expression profiling analysis and experimental validation. Oncotarget 6 : 37544-37556.

Cleynen I, Van de Ven WJM (2008) The HMGA proteins: a myriad of functions (Review). Int J Oncol 32: 289-305.

Esquela-Kerscher A, Slack FJ (2006) Oncomirs-microRNAs with a role in cancer. Nat Rev Cancer 6: 259-269.

Fedele M, Bandiera A, Chiappetta G, Battista S, Viglietto G, Manfioletti G, Casamassimi A, Santoro M, Giancotti V, Fusco A (1996) Human colorectal carcinomas express high levels of high mobility group HMGI(Y) proteins. Cancer Res 56: 1896-1901.

Gasparini P, Lovat F, Fassan M, Casadei L, Cascione L, Jacob NK, Carasi S, Palmieri D, Costinean S, Shapiro CL, Huebner K, Croce CM (2014) Protective role of miR-155 in breast cancer through RAD51 targeting impairs homologous recombination after irradiation. Proc Natl Acad Sci USA 111: 4536-4541.

Haggar FA, Boushey RP (2009) Colorectal cancer epidemiology: incidence, mortality, survival, and risk factors. Clin Colon Rectal Surg 22: 191-197.

Hawes SE, Kiviat NB (2002) Are genital infections and inflammation cofactors in the pathogenesis of invasive cervical cancer? J Natl Cancer Inst 94: 1592-1593.

Hillion J, Dhara S, Sumter TF, Mukherjee M, Di Cello F, Belton A, Turkson J, Jaganathan S, Cheng L, Ye Z, Jove R, Aplan P, Lin YW, Wertzler K, Reeves R, Elbahlouh O, Kowalski J, Bhattacharya R, Resar LMS (2008) The high-mobility group A1a/signal transducer and activator of transcription3 axis: an Achilles heel for hematopoietic malignancies? Cancer Res 68: 10121-10127.

Hu X, Schwarz JK, Lewis JS, Huettner PC, Rader JS, Deasy JO, Grigsby PW, Wang X (2010) A microRNA expression signature for cervical cancer prognosis. Cancer Res 70: 1441-1448.

Huang M-L, Chen C-C, Chang L-C (2009) Gene expressions of HMGI-C and $\mathrm{HMGI}(\mathrm{Y})$ are associated with stage and metastasis in colorectal cancer. Int J Colorectal Dis 24: 1281-1286. 
Hur K, Toiyama Y, Schetter AJ, Okugawa Y, Harris CC, Boland CR, Goel A (2015) Identification of a metastasis-specific microRNA signature in human colorectal cancer. J Natl Cancer Inst 107: 1-11.

Kaddar T, Rouault J-P, Chien WW, Chebel A, Gadoux M, Salles G, Ffrench M, Magaud J-P (2009) Two new miR-16 targets: caprin-1 and HMGA1, proteins implicated in cell proliferation. Biol Cell 101: 511-524.

Krek A, Grün D, Poy MN, Wolf R, Rosenberg L, Epstein EJ, MacMenamin P, da Piedade I, Gunsalus KC, Stoffel M, Rajewsky N (2005) Combinatorial microRNA target predictions. Nat Genet 37: 495-500.

Kuninty PR, Schnittert J, Storm G, Prakash J (2016) MicroRNA targeting to modulate tumor microenvironment. Front Oncol 6: 3.

Lewis BP, Shih IH, Jones-Rhoades MW, Bartel DP, Burge CB (2003) Prediction of mammalian microRNA targets. Cell 115: 787-798.

Lin Y, Chen H, Hu Z, Mao Y, Xu XX, Zhu Y, Xu XX, Wu J, Li S, Mao Q, Zheng X, Xie L (2013) MiR-26a inhibits proliferation and motility in bladder cancer by targeting HMGA1. FEBS Lett 587: 2467-2473.

Long L-M, He B-F, Huang G-Q, Guo Y-H, Liu Y-S, Huo J-R (2015) microRNA-214 functions as a tumor suppressor in human colon cancer via the suppression of ADP-ribosylation factor-like protein 2. Oncol Lett 9: 645-650.

Lund T, Holtlund J, Fredriksen M, Laland SG (1983) On the presence of two new high mobility group-like proteins in HeLa S3 cells. FEBS Lett 152: 163-167.

Mellone M, Rinaldi C, Massimi I, Petroni M, Veschi V, Talora C, Truffa S, Stabile H, Frati L, Screpanti I, Gulino A, Giannini G (2008) Human papilloma virus-dependent HMGA1 expression is a relevant step in cervical carcinogenesis. Neoplasia 10: 773-781.

Moghimi-Dehkordi B (2012) An overview of colorectal cancer survival rates and prognosis in Asia. World J Gastrointest Oncol 4: 71.

Mohandas KM (2011) Colorectal cancer in India: controversies, enigmas and primary prevention. Indian J Gastroenterol 30: 3-6.

Pedersen IM, Otero D, Kao E, Miletic AV, Hother C, Ralfkiaer E, Rickert RC, Gronbaek K, David M (2009) Onco-miR-155 targets SHIP1 to promote TNF $\alpha$-dependent growth of B cell lymphomas. EMBO Mol Med 1: 288-295.

Peng R-Q, Wan H-Y, Li H-F, Liu M, Li X, Tang H (2012) MicroRNA-214 suppresses growth and invasiveness of cervical cancer cells by targeting UDP-N-acetyl- $\alpha$-D-galactosamine:polypeptide $\mathrm{N}$-acetylgalactosaminyltransferase 7. J Biol Chem 287: 14301-14309.

Penna E, Orso F, Cimino D, Vercellino I, Grassi E, Quaglino E, Turco E, Taverna D (2013) MiR-214 coordinates melanoma progression by upregulating ALCAM through TFAP2 and miR-148b downmodulation. Cancer Res 73: 4098-4111.

Pereira PM, Marques JP, Soares AR, Carreto L, Santos MaS (2010) Microrna expression variability in human cervical tissues. PLoS One 5: e11780.

Qiu B, Han W, Tergaonkar V (2015) NUCKS: a potential biomarker in cancer and metabolic disease. Clin Sci (Lond) 128: 715-721.

Qiu B, Shi X, Wong ET, Lim J, Bezzi M, Low D, Zhou Q, Akıncılar SC, Lakshmanan M, Swa HLF, Tham JML, Gunaratne J, Cheng KKY, Hong W, Lam KSL, Ikawa M, Guccione E, Xu A, Han W, Tergaonkar V (2014) NUCKS is a positive transcriptional regulator of insulin signaling. Cell Rep 7: 1876-1886.

Reeves R, Edberg DD, Li Y (2001) Architectural transcription factor HMGI(Y) promotes tumor progression and mesenchymal transition of human epithelial cells. Mol Cell Biol 21: 575-594.

Resar LMS (2010) The high mobility group A1 gene: transforming inflammatory signals into cancer? Cancer Res 70: 436-439.
Saito K, Oku T, Ata N, Miyashiro H, Hattori M, Saiki I (1997) A modified and convenient method for assessing tumor cell invasion and migration and its application to screening for inhibitors. Biol Pharm Bull 20: 345-348.

Sankaranarayanan R, Swaminathan R, Black RJ (1996) Global variations in cancer survival. Cancer 78: 2461-2464.

Savita U, Karunagaran D (2013) MicroRNA-106b-25 cluster targets $\beta$-TRCP2, increases the expression of Snail and enhances cell migration and invasion in H1299 (non small cell lung cancer) cells. Biochem Biophys Res Commun 434: 841-847.

Subramanian M, Rao SR, Thacker P, Chatterjee S, Karunagaran D (2014) MiR-29b downregulates canonical Wnt signaling by suppressing coactivators of $\beta$-catenin in human colorectal cancer cells. J Cell Biochem 115: 1974-1984.

Suzuki HI, Katsura A, Matsuyama H, Miyazono K (2014) MicroRNA regulons in tumor microenvironment. Oncogene 34: 3085-3094.

Wang F, Liu M, Li X, Tang H (2013) MiR-214 reduces cell survival and enhances cisplatin-induced cytotoxicity via down-regulation of Bcl212 in cervical cancer cells. FEBS Lett 587: 488-495.

Wei J-JJ, Wu X, Peng Y, Shi G, Olca B, Yang X, Daniels G, Osman I, Ouyang J, Hernando E, Pellicer A, Rhim JS, Melamed J, Lee P, Basturk O, Olca B, Yang X, Daniels G, Osman I, Ouyang J, Hernando E, Pellicer A, Rhim JS, Melamed J, Lee P (2011) Regulation of HMGA1 expression by MicroRNA-296 affects prostate cancer growth and invasion. Clin Cancer Res 17: 1297-1305.

Wen Z, Lei Z, Jin-An M, Xue-Zhen L, Xing-Nan Z, Xiu-Wen D (2014) The inhibitory role of miR-214 in cervical cancer cells through directly targeting mitochondrial transcription factor A (TFAM). Eur J Gynaecol Oncol 35: 676-682.

Xing J, Cao G, Fu C (2014) HMGA1 interacts with beta-catenin to positively regulate Wnt/beta-catenin signaling in colorectal cancer cells. Pathol Oncol Res 20: 847-851.

Xu G, Wang J, Jia Y, Shen F, Han W, Kang Y (2014) MiR-142-3p functions as a potential tumor suppressor in human osteosarcoma by targeting HMGA1. Cell Physiol Biochem 33: 1329-1339.

Yang H, Kong W, He L, Zhao J-J, O'Donnell JD, Wang J, Wenham RM, Coppola D, Kruk Pa, Nicosia SV, Cheng JQ (2008) MicroRNA expression profiling in human ovarian cancer: miR-214 induces cell survival and cisplatin resistance by targeting PTEN. Cancer Res 68: 425-433.

Yang T-S, Yang X-H, Wang X-D, Wang Y-L, Zhou B, Song Z-S (2013) MiR214 regulate gastric cancer cell proliferation, migration and invasion by targeting PTEN. Cancer Cell Int 13: 68.

Yang Z, Chen S, Luan X, Li Y, Liu M, Li X, Liu T, Tang H (2009) MicroRNA214 is aberrantly expressed in cervical cancers and inhibits the growth of HeLa cells. IUBMB Life 61: 1075-1082.

Zu X, Zhong J, Tan J, Tan L, Yang D, Zhang Q, Ding W, Liu W, Wen G, Liu J, Cao R, Jiang Y (2015) TGF- $\beta 1$ induces HMGA1 expression in human breast cancer cells: Implications of the involvement of HMGA1 in TGF- $\beta$ signaling. Int J Mol Med 35: 693-701.

Zur Hausen H (1996) Papillomavirus infections-a major cause of human cancers. Biochim Biophys Acta 1288: F55-F78.

This work is published under the standard license to publish agreement. After 12 months the work will become freely available and the license terms will switch to a Creative Commons AttributionNonCommercial-Share Alike 4.0 Unported License. 